\title{
Culture and Causality: An Anthropological Comment
}

\author{
TOM FRICKE
}

\begin{abstract}
Our discussion will be adequate if it has as much clearness as the subject-matter admits of, for precision is not to be sought for alike in all discussions, any more than in all the products of the crafts.... In the same spirit, therefore, should each type of statement be received; for it is the mark of an educated man to look for precision in each class of things just so far as the nature of the subject admits; it is evidently equally foolish to accept probable reasoning from a mathematician and to demand from a rhetorician scientific proofs.
\end{abstract}

Aristotle (McKeon 1992: 329)

It is sometimes said, either irritably or with a certain satisfaction, that philosophy makes no progress. It is certainly true, and I think this is an abiding and not regrettable characteristic of the discipline, that philosophy has in a sense to keep trying to return to the beginning: a thing which is not at all easy to do.

Iris Murdoch (1970: 1)

If ANTHROPOLOGY is to contribute anything distinctly its own to a discussion of causality, the contribution will best come through its specialization in culture. An anthropologist would not be your first choice for statistical advice on the applicability of discrete- or continuous-time models in an eventhistory analysis. Even in the most elementary quantitative applications, anthropological texts defer to the work of more expertly trained others (Thomas 1976; Bernard 1988). Fortunately, demographers want anthropological insights in precisely those areas of cultural meaning about which they assume anthropologists are most prepared to speak. The general understanding, mostly unstated, is that anthropologists have a set of procedures and understandings that enable them to make interpretations of the meanings of variables with a degree of reliability that untrained others lack. Along 
with that faith goes the also unstated understanding that the concept called "culture" is underlain by a long history of shared and increasingly perfected definitional rigor.

It is something of a shock for those from outside anthropology, then, to discover the near chaos of argument on just what culture is, much less the proper approaches to studying it. Eugene Hammel's influential 1990 article, "A theory of culture for demography," lifted the lid off the current state of those arguments within anthropology. Rhetorically powerful, fun to read, and often on the mark, it is one of the best surveys of the culture concept available to demography. It is also profoundly pessimistic in that it declares the two things that demographers have most wanted from anthropology, a theory of motivation for behavior and a theory of the meaningful contexts in which behavior occurs, to be the very two things they cannot have (1990: 466-467).

David Kertzer followed this essay a few years later (I997) with his own review of some of the same material. He placed the central tensions into the dichotomy between exclusively economic or exclusively cultural theories of causality. Against these, Kertzer suggested the possibility of a "third way" that seems to disavow the value of interpretive approaches to culture represented, despite all their differences, by Clifford Geertz and his intellectual descendents.

My own work bears some of the characteristics that Hammel and Kertzer criticize. That is, I believe demographers are asking exactly the right questions of anthropology-though they may not like the implications of the answers. Many interpretive approaches are representative of some of the best of what anthropology has to offer to our understanding of causality in demographic processes. This follows from how we understand causality itself. Much of the literature has to do with bolstering the analyst's surety that the correlations between variables are not spurious, but all agree with the most basic point that such analysis "cannot be directly used to establish causality because...correlations merely measure covariation" (Blalock 1972: 442). In other words, all arguments about causality involve interpretive decisions. This is probably too elementary to belabor, but it opens the window for using specific ideas about culture in ways that can be applied to demographic problems.

My argument assumes that we want to know how those processes work in particular settings. To the extent that what we seek to understand involves a particular place and particular people, interpretation is a necessary part of that understanding. This sketch is quickly outlined as follows: the only enduring contribution that cultural anthropology can make to demographic research is in terms of meaning, which implies interpretation; the best interpretive models available are expressed in terms of patterns of meaning and motivation; these models, like all others, are not independent of a view of 
human beings; this view of the subject may have implications for our rules of argument and for defending the validity of any particular causal explanation.

\section{Anthropological contributions}

The history of anthropological demography suggests that, lacking a theory of culture, anthropology's contribution to demography could be reduced to the recruitment of high-priced area and language specialists as adjuncts to larger projects. Other than the area specializations, it is largely through the introduction of cultural issues that anthropology offers additional insight into demographic analysis. Looking at the range of studies that exist, and recognizing that any single study crosses categories, reveals three general kinds of anthropological contribution: (1) the replication of standard demographic data collection and analysis among small, exotic, or hard-to-reach populations; (2) the reinterpretation of existing survey data and the addition of new, locally relevant variables to social surveys; and (3) the application of cultural understandings and contexts to strategies of data collection and analysis. Examples of the first might include early work by British anthropologists in Africa (Fortes 1943; Barnes 1949) and more recent work by scholars such as Alan Fix (1977) and Nancy Howell (1979); of the second, work from Pakistan (Fricke, Syed, and Smith 1986), Africa (Lesthaeghe 1989), and Taiwan (Thornton and Lin 1994); and of the third, a wide and disparate set with examples in edited volumes such as Greenhalgh (1995a) and Kertzer and Fricke (1997).

Of the three kinds of contribution, the first has declined in dominance as well-conceived social surveys are able to be carried out in increasingly remote settings (Axinn, Barber, and Ghimire 1997). The second two have correspondingly risen in importance, their distinguishing feature being that both demand the cultural expertise of the anthropologist to be at all effective. We are faced, then, with needing a definition of culture that is both, pace Hammel, useful for demography and true to its subject.

In my own work (most explicitly in 1997a, 1997b), I have argued that the most useful theory of culture for demography would begin from models that take it as defining the world of action and providing the motivations for action in that world. Not only are these exactly the areas that Hammel has diagnosed as being of greatest interest to demographers themselves, but they are also elements embedded in several definitions of culture by anthropologists. These anthropologists include some of greater and lesser theoretical currency, from the now 30-year-old statement by Clifford Geertz that takes culture as models of and for reality (1973) to more recent work by cognitive anthropologists (D'Andrade 1995; Strauss and Quinn 1998). The points made independently and vigorously by such writers as Hammel (1990), Kertzer (1997), and Greenhalgh (1995b) concerning the 
labile and shifting nature of cultural meanings are not inherently incompatible with this kind of orientation to culture. Nor are their criticisms of some of the more serious misuses of "culture" in multivariate models. It is nevertheless also important to stress that there must be some minimal level of stability in the shared understandings and the bounds of groups within which these understandings hold to maintain social discourse. The extent of that stability is what may determine how these understandings can be used in particular causal arguments, but these are the things that require case-by-case argument.

Many practitioners associated with interpretive theories of culture would themselves be uncomfortable with the application of their understandings of culture to multivariate causal analyses. Some of that discomfort must derive from the procedural assumptions of much empirical social science, assumptions which imply a view of the person that is strikingly at odds with most of our own experiences of everyday life. This suggests that the use of these models may have implications for how strongly we assert the necessity of certain procedural rules, most of which were developed and later enshrined to provide interpretive assurance across the empirical divide that separates causation in the world from our ideas about it (Menand 2001: 262).

The dilemma of culture is that, unlike those causal relationships in which an external force or agent moves an object, culture is a context of understanding and motivation that must be inside of the person. If we see culture as an external force, then we are unable to account for its fluidity and openness to change. If we fail to see it as internalized in human beings who need to operate in terms of continuity and common understandings, then we risk losing insights into its ability to endure through time. This isn't the place to discuss that process of internalization except to say that we have a reasonable understanding of how a person grows into a culture in our theories of human development, socialization, and enculturation. In some ways, culture gets into us as does a habit.

Thinking of culture this way gets us out of the problem of using it in the old determinative ways of sets of laws or norms, approaches Hammel called "mired in structural-functional concepts that are about 40 years old, hardening rapidly, and showing every sign of fossilization" (1990: 456). It gets us thinking in complex ways about how frameworks of meaning provide a logic for human action in the concrete circumstances and histories of real actors. There is room simultaneously for life course theories and their variables, political economic theories and their variables, and interpretive understandings of culture. But, at the same time, there are implications for how we develop our hypotheses and defend our explanations. Let me give examples in two areas of concern for demography, aggregate and individuallevel analyses, both of which make use of this idea of culture as frame of meaning and motivation. 


\section{Aggregate explanation}

It is easy enough to invoke culture for the aggregate-level differences we notice in demographic phenomena across groups. The groups are usually defined by either geography or ethnicity or, more questionably, religion, and often by a combination of these. An older causal use of these variables might be summarized as "These $X$ kind of people have more children or marry younger because their culture has norms or rules that tell them to behave this way."

A more subtle way of using these variables might be to notice a social practice, cross-cousin marriage for example, that is more prevalent in population $X$ than population $Y$. Tim Dyson and Mick Moore (1983) did something like this in an extremely valuable comparison of North and South India that focused on women's status as linked to systems of marriage, making that the proximate cause for later ages at marriage and lower fertility in South India than in the North.

A cultural explanation in terms of frameworks of meaning and motivation might go a step further and argue that in those areas with crosscousin marriage systems an ethos of reciprocal alliances operates as a governing framework for interpreting and motivating behaviors. That system has important connections to the symbolic role of marriage in those alliances, to the continuing identity of women with respect to their natal families after marriage, and to the degree to which the families and even whole lineages united by marriage exchanges see themselves as sharing ancestry. It actually gets much more complex than this. Although I have not worked in South India, my generalizations come from my own fieldwork in another population favoring cross-cousin marriage and my knowledge of ethnographies about other settings. North Indian populations could very crudely be contrasted with South Indian on these same dimensions.

The point here is not to play this out in detail but to denote the general emphasis on meaning. My point about the potential problems of religion used in this general way is that religions often cross regions with vastly different cultural systems in other respects. And this suggests a crucial problem with identifying the bounds of cultural context. This is an empirical problem, but still very real: How do we comfortably bound populations for whom we can say that the attributes of culture are shared? On the one hand, we want to be able to say something that applies to a bounded group; on the other, we are in constant danger of committing the ecological fallacy. This seems to be a problem with any aggregate analysis, but saying this does not make the problem go away. In anthropological circles, these kinds of arguments run the serious risk of "essentializing" people, and here again is the concern for choosing framing elements of meaning that can be plausibly defended. 


\section{Individual explanation}

Pulling this perspective down to the individual level will help to make the point that quite concrete measures can be interpreted in cultural terms. One of the classic "modernization" variables in the demographic analysis of age at marriage is education. Across the world few relationships are more consistent than the positive one between these two measures: any schooling at all seems to be related to later ages at marriage; and the higher the schooling levels, the greater the age at marriage. Nevertheless, our understanding of this relationship is deeply interpretive. We rarely say "education causes later marriage" and leave it at that. Older demographic transition theory took education to be an indicator of modernization and argued that it was correlated with secularization, increased rationality, and heightened individual autonomy. Even the successors to this theory seldom question the common meaning of education across settings. Their interpretations of its impact on other variables may differ, as for example when they suggest that parental desires to educate their children keep the latter out of the marriage market longer. The explanations for a positive relationship between age at marriage and educational attainment have two basic forms in these different approaches. One focuses on the autonomy it confers on individual children (modernization theory) and the other allows for parental controls over the marriage timing of children but suggests a fairly mechanical relationship between the incompatibility of schooling and marriage.

But neither of these explanations is concerned with the specific meaning of education in context, and this might vary considerably across settings. In our analysis of survey data from rural Punjabi villages, my colleagues and I (Fricke, Syed, and Smith 1986) noted that a woman's education had the usual positive relationship with age at marriage even when controls for numerous other individual characteristics were accounted for. An analyst might be tempted to interpret these results in terms of a modernization framework: education leads to greater autonomy, which leads to more control over one's destiny and results in higher ages at marriage. But the results also show that the substantial fraction of women who attended school only briefly, without completing a year, marry at later ages than those who never attended school at all.

Neither demographic transition theory's explanation nor the incompatibility explanation works for these relationships. My coauthors and I argued that the relationship could not be understood without reference to highly specific features of the local context. We argued that education had become part of a larger world of symbolic indicators of status and that any schooling at all conferred a standing on the natal family of a woman and allowed them to wait longer to marry off their daughter since this status counterbalanced the loss of a woman's value in marriage as a result of increasing age. 
We noted that the relationship between education and employment was hardly relevant here. Women in this setting were not likely to be serious supporters of their families in monetary work, certainly not in monetary work requiring education. We also noted that all marriages in this setting were arranged. The failure of standard explanations that ignored context caused us to turn to the ethnographic literature on Punjabi marriages. We focused on literature that discussed marriage within the context of wider relationships organized by family and kinship, including material on the symbolic significance of women, the relation between person and group, the social organization of marriage, prestige systems, and cultural theories of personhood and gender. Our interpretation of education as a marker of quality, influencing the desirability of connections between families organized by marriage, placed the experience of schooling within a wider array of prestige markers that play a part in marriage negotiation. The actual educational content, and the implications for autonomy in a setting where no woman chooses her own spouse, were secondary to our thinking.

Our examination of schooling converted the measure from a story about education to a culturally meaningful symbol that made a statement about a woman's family. In so doing, we drastically altered the possible interpretation of an empirical relationship. In the same way any researcher is concerned with plausibility, our interpretation trumped received models devoid of cultural content because it more coherently accounted for what was anomalous in these other models. It did so, moreover, using a framework that established a consistent culture-based story for all other variables in the analysis.

\section{The nature of the subject}

There are, of course, no neutral ways of approaching the human subject (Putnam 2002). Each approach implies an underlying orientation; and, conversely, to argue for an orientation or that some characteristics are more essentially human than others is to argue that some approaches are better attuned to these characteristics than others. Those discussions of research design that suggest otherwise-that one can leave out the "philosophical" issues to arrive at sound method (King, Keohane, and Verba 1994)-need to ask how standardizing analytic procedures across all cases may inadvertently impoverish understanding. Iris Murdoch argued that her objection to a particular image of the human subject prevalent in analytic strategies was empirical, philosophical, and moral all at once (1970: 8-9).

Many discussions of culture and meaning have a disembodied and abstract quality. They favor principle and abstraction to such an extent that it is easy to forget that understanding a human subject is the reason for the discussion at all. One advantage of the interpretive orientation is that it makes it harder to lose sight of this. Charles Taylor, a key source for this orienta- 
tion, suggests that the essential character of the human subject is the capacity for self-interpretation and action in terms of meaning. For him, "human behavior seen as action of agents who desire and are moved, who have goals and aspirations, necessarily offers a purchase for descriptions in terms of meaning" (Taylor 1985: 27).

It is true, as Hammel implies, that we cannot get inside people's heads to actually know what motivates them or how they see the world. It is true, in other words, that we operate in terms of theories. But this is the same context within which we live our everyday lives. If I ask myself the question in my everyday dealings with people, "Why did she do that?," I seek an answer as an attempt to understand that person's view of the world, her motivations, and the concrete circumstances of a situation. I acknowledge, if I want to get as close to the true reasons as possible, that I might be wrong in my interpretation and that more information, or the reach for more consistency in light of the available information, may cause me to modify my initial understanding. If the thing I seek to explain is important, or if the person is particularly important to me, I may try to include information about her past history and wider networks of kin and association.

In some ways, anthropological fieldwork replicates this prosaic operation of the everyday. Our attempts at understanding are imaginative acts in which we try to get inside of the head of the cultural other. More concretely, when we try to generalize about systems of meaning and motivation or try to think about what we need to know to explain the causes of a behavior or event in a given setting, we have real people in mind. The experience of the field seems to reduce procedural worries. An especially pertinent example for demography is John Caldwell, whose account of his movement into ethnographic forms of study (1982: 3-5) has the feel of conversion. His experience of "becoming intimately acquainted with each village and its families" (1982: 4) underwrites his subsequent flexibility in approaches to deriving conclusions from field data (Caldwell, Reddy, and Caldwell 1988: 68).

\section{Some implications}

It may seem that these comments have wandered far from the issue of causality. For those who want to hold to the technical and restricted sense (Rosenberg 1968: I0), this may be the case. But since, "empirically, we can...never prove that the connection between two variables is necessary" (Blalock 1972: 449; cf. Menand 2001: 262 on David Hume), the discussion of causality necessarily takes us into what Blalock has called theoretical language, in this case a meta-theoretical language that suggests that the interpretation of variables may not be as straightforward as we would like. Hammel's point that there are no independent measures of meaning or motivation is a recognition that what goes on inside a person's head is ultimately private. This seems irreducibly so. 
Yet, if causal relations are themselves unobservable, then the procedures we use to explore causality are themselves conventions developed and sustained because they have worked so well for certain kinds of problems. To suggest this much is not to argue that they are without value, but to open the possibility to alternative procedures. Aristotle's point in the epigraph was at least partly to argue that method and expectation should be appropriate to the subject. It may be that those procedures that work well in natural sciences-where the subjects are not self-reflective, conscious, and moral beings, as interpretive approaches to the human sciences imply-are too confining for the study of causality in human beings (Taylor 1964, 1985).

The unobservability of causal relations means that our conventions for arguing them are another "trick of the trade," as Howard Becker argues (1998: 63-66). Descriptions of culture are necessarily descriptions of systems of meaning requiring different criteria of validity than the causal explanations appropriate to individual variation. The primary criterion of an adequate description is its coherence (Taylor 1985).

This may be the most difficult characteristic of this approach to culture and causality for demographers to accept. It requires a different form of argument and greater openness to reformulation than is typical for the usual analytic verifications of quantitative analyses. Its rewards are found in more nuanced and contextualized discussions of meaning based on local criteria and, ultimately, the people who are themselves the subject of study.

\section{Note}

Many thanks to Christine Bachrach for her prescient organization of the session at the Annual Meeting of the Population Association of America (May 2003, Minneapolis) for which this comment was crafted. And special thanks to her and the session discussant,
Geoffrey McNicoll, for their probing, witty, and elegant comments on the draft manuscript. William Axinn, Jennifer Barber, Robert Moffitt, Nancy Riley, Herbert Smith, and Arland Thornton also sparked ideas and revisions.

\section{References}

Axinn, William G., Jennifer S. Barber, and Dirgha Ghimire. 1997. "The neighborhood history calendar: A data collection method designed for dynamic multilevel modeling," in A. E. Raftery (ed.), Sociological Methodology. Cambridge, MA: Blackwell Publishers, pp. 355-392.

Barnes, John A. 1949. "Measures of divorce frequency in simple societies," Journal of the Royal Anthropological Institute 79: 37-62.

Becker, Howard S. 1998. Tricks of the Trade: How to Think About Your Research While You're Doing It. Chicago: University of Chicago Press.

Bernard, H. Russell. 1988. Research Methods in Cultural Anthropology. Newbury Park: Sage Publications.

Blalock, Hubert M., Jr. 1972. Social Statistics. New York: McGraw-Hill. 
Caldwell, John C. 1982. Theory of Fertility Decline. New York: Academic Press.

Caldwell, John C., P. H. Reddy, and Pat Caldwell. 1988. The Causes of Demographic Change: Experimental Research in South India. Madison: University of Wisconsin Press.

D'Andrade, Roy. 1995. The Development of Cognitive Anthropology. New York: Cambridge University Press.

Dyson, Tim and Mick Moore. 1983. “On kinship structure, female autonomy, and demographic behavior in India," Population and Development Review 9(1): 35-60.

Fix, James. 1977. "The demography of the Semai Senoi," Anthropological Papers of the Museum of Anthropology, University of Michigan, No. 62.

Fortes, Meyer. 1943. "A note on fertility among the Tallensi of the Gold Coast," Sociological Review 35(4,5): 99-113.

Fricke, Tom. 1997a. "Culture theory and population process: Toward a thicker demography," in David I. Kertzer and Tom Fricke (eds.), Anthropological Demography: Toward a New Synthesis. Chicago: University of Chicago Press, pp. 248-277.

-1997b. "Marriage change as moral change: Culture, virtue, and demographic transition," in Gavin W. Jones, Robert M. Douglas, John C. Caldwell, and Rennie M. D'Souza (eds.), The Continuing Demographic Transition. Oxford: Oxford University Press, pp. 183-212.

Fricke, Tom, Sabiha Syed, and Peter C. Smith. 1986. "Rural Punjabi social organization and marriage timing strategies in Pakistan," Demography 23(4): 489-508.

Geertz, Clifford. 1973. The Interpretation of Cultures. New York: Basic Books.

Greenhalgh, Susan (ed.). 1995a. Situating Fertility: Anthropology and Demographic Inquiry. Cambridge: Cambridge University Press.

- 1995b. "Anthropology theorizes reproduction: Integrating practice, political economic, and feminist perspectives," in Susan Greenhalgh (ed.). Situating Fertility: Anthropology and Demographic Inquiry. Cambridge: Cambridge University Press, pp. 3-28.

Hammel, E. A. 1990. "A theory of culture for demography," Population and Development Review 16(3): 455-485.

Howell, Nancy. 1979. The Demography of the Dobe IKung. New York: Academic Press.

Kertzer, David I. 1997. "The proper role of culture in demographic explanation," in Gavin W. Jones, Robert M. Douglas, John C. Caldwell, and Rennie M. D'Souza (eds.), The Continuing Demographic Transition. Oxford: Oxford University Press, pp. 137-157.

Kertzer, David I. and Tom Fricke (eds.). 1997. Anthropological Demography: Toward a New Synthesis. Chicago: University of Chicago Press.

King, Gary, Robert O. Keohane, and Sidney Verba. 1994. Designing Social Inquiry: Scientific Inference in Qualitative Research. Princeton: Princeton University Press.

Lesthaeghe, Ron J. (ed.). 1989. Reproduction and Social Organization in Sub-Saharan Africa. Berkeley: University of California Press.

McKeon, Richard (ed.). 1992. Introduction to Aristotle. New York: Modern Library.

Menand, Louis. 2001. The Metaphysical Club: A Story of Ideas in America. New York: Farrar, Straus and Giroux.

Murdoch, Iris. 1970. The Sovereignty of Good. London: Routledge \& Kegan Paul.

Putnam, Hilary. 2002. The Collapse of the Fact/Value Dichotomy and Other Essays. Cambridge, MA: Harvard University Press.

Rosenberg, Morris. 1968. The Logic of Survey Analysis. New York: Basic Books.

Strauss, Claudia and Naomi Quinn. 1998. A Cognitive Theory of Cultural Meaning. Cambridge: Cambridge University Press.

Taylor, Charles. 1964. The Explanation of Behaviour. London: Routledge $\boldsymbol{\sigma}$ Kegan Paul.

. 1985. "Interpretation and the sciences of man," in Philosophy and the Human Sciences. Cambridge: Cambridge University Press, pp. 15-57.

Thomas, David Hurst. 1976. Figuring Anthropology: First Principles of Probability and Statistics. New York: Holt, Rinehart, and Winston.

Thornton, Arland and Hui-Sheng Lin. 1994. Social Change and the Family in Taiwan. Chicago: University of Chicago Press. 